\title{
EM TORNO A \\ EMMANUEL MOUNIER
}

Alino Lorenzon

$U G F$

MOUNIER, Emmanuel. Refaire La Remnaissance. Préface de Guy Coq. Paris: Le Seuil, 2000. 517 p. (Essais, 413).

\begin{abstract}
E mmanuel Mounier faleceu há cinqüenta anos, em plena atividade intelectual aos quarenta e cinco anos. A morte interrompeuIhe todo um projeto de vida. Uma grande figura do século XX, fundador da revista e do movimento Esprit em 1932, na idade de vinte e cinco anos. A revista Esprit continua ainda hoje como canal de discussão e como uma das mais influentes e de maior tiragem na França.

Mounier desempenhou para sua época e para muitos homens e mulheres um papel excepcional de educador e de filósofo no sentido mais radical da palavra. É por isso que neste ano muitos eventos têm sido programados em diversos países e sobretudo na França com estudos, discussões, congressos e publicações, aprofundando sua obra, seu pensamento e seu testemunho à luz da problemática de hoje. $\mathrm{O}$ maior evento está previsto para os dias 4, 5 e 6 de outubro na UNESCO, em Paris, com a realização do Colóquio Internacional Emmantuel Montnier: um grand témoin.
\end{abstract}


A coordenação geral do colóquio ficou a cargo de Guy Coq, Presidente e membro da Association dês anies d'E. Mounier, da redação de Esprit. Dentre as múltiplas atividades programadas, além do Colóquio Internacional, constam iniciativas editoriais como publicação de inéditos, reedições, trabalhos sobre a obra de Mounier, traduçóes, artigos, debates na imprensa, sites na internet e outros. Assim é que a obra da qual redigimos esta resenha acaba de ser selecionada e reunida com excelente prefácio de Guy Coq. São alguns textos fundadores, em particular artigos de Esprit. O título Refaire la Rennaisance foi dado ao manifesto na reunião em Font-Romeu nos Pireneus, em outubro de 1932, quando um grupo de jovens intelectuais franceses, inconformados com os rumos da civilização burguesa e individualista e com um certo cristianismo comprometido com a mesma, decidiram lançar um movimento e uma revista destinados a pensar uma nova civilização mais justa e mais solidária e se engajar ao mesmo tempo para a realização do projeto.

O título Refazer a Renascenţa poderá parecer à primeira vista um tanto estranho. O Renascimento propõe uma mudança radical em face de um mundo em decadência. Assim, na década de 1930, precisava diagnosticar uma crise global duma civilização, também decadente, inaceitável por aquelas novas gerações, mais lúcidas.

Guy Coq o ressalta muito bem, no prefácio, ao levantar a questão: Qunl civilizaç̃̆to? A um mundo totalmente dominado pelo individualismo burguês e pelas ameaças dos coletivismos, a uma filosofia idealista distanciada dos graves problemas da realidade, era preciso opor um novo projeto de civilização, uma filosofia voltada para a discussão desses novos desafios e um cristianismo mais fiel à mensagem e aos exemplos de Jesus Cristo. Para tanto era necessária a audácia da juventude, que sofria na carne as conseqüências da crise econômica e da Primeira Guerra Mundial. Era necessária a pobreza do santo e, podese mesmo dizer, a força do profeta.

Paul Ricoeur, num texto que discerne a profundeza essencial do gênio, insiste na necessidade de jamais esquecer essa ambição primeira de Mounier que subentende a toda a obra do fundador de Esprit (p. 10).

Quando Mounier discute a pessoa, a comunidade, a economia, a política, a religião ou qualquer outro campo do saber e do agir humanos e da sociedade, é preciso lembrar que esses são aspectos parciais tendo sentido unicamente dentro de um projeto global - a civilização.

O texto de Paul Ricoeur, citado e comentado por Guy Coq, captou muito bem a intuição do fundador de Esprrit. "Sua grande força foi a de ter, em 1932, ligado a origem de sua maneira de filosofar à tomada de consciência duma crise de civilização e de ter ousado visar, além de toda filosofia de escola, uma nova civilização em sua totalidade" (Une philosophie, Esprit, n. 12 (1950): 861). Esse número de Esprit foi totalmente consagrado a Mounier alguns meses após sua morte. 
É importante ressaltar que na década de 30 as discussões filosóficas e sobretudo econômicas se cristalizavam em torno de diagnósticos parciais (crise econômica, crise moral, crise espiritual, crise política...). Mounier denuncia uma gravíssima crise de civilização. Diante de um mundo que desaba será preciso intuir a gestação de um novo mundo. Mounier afirmará que a crise é ao mesmo tempo econômica e moral, e que será urgente restabelecer o "primado do espiritual não de maneira exclusivista, lembrando, ao mesmo tempo que para a pessoa há 'outros valores que estão em marcha'". Para tanto, nada melhor que ler o texto do manifesto publicado na íntegra no livro em apreço (pp. 37-80).

A obra, portanto, que pretendemos resenhar, reúne alguns textos fundadores de Esprit. São três textos muito densos, assim intitulados. Revoluçáo personalista e comunitária, Da propriedade capitalista à propriedade humana e Personalismo e cristianismo. Esses textos constam do tomo I das Oeutres - 1931-1939, reunidos por Mme. Pauletti Mounier e editados pelas Editions du Seuil em 1961.

I - Revolufão personalista e comunitária, publicado pela primeira vez em 1935, desenvolve de certa maneira as principais intuições e intenções de Mounier. Há uma profunda crise de civilização, da civilização burguesa e capitalista e da cristandade. Por isso, a própria filosofia deverá pensar a problemática e os desafios desse momento histórico com um novo discurso que lhe possibilite uma estreita articulação dialética com a ação (o engajamento).

O título do texto (Rezoluçăo...) é muito significativo e desafiador. Essa revolução, segundo Mounier e o grupo de jovens inconformistas que a ele se juntaram numa comunhão de idéias, terá como núcleo orientador o binômio pessoa e comunidade. Esses dois conceitos e essas duas realidades constituirão uma luz e uma força, permanentemente presentes, como pode ser constatado pela leitura e pela análise do texto acima, dividido em três seções.

1. Linhas de partida estabelecem como que os fundamentos dum programa de reflexão e de ação. Diante da crise global duma civilização desmoronando, Mounier propõe Refazer a Renascença, mediante uma revolução que se inspirasse numa nova visão de pessoa e de comunidade. Ao proclamar a necessidade de refazer a Renascença, Mounier pretendia mostrar que, assim como os mentores daquele movimento tomaram consciência dum mundo que estava acabando, era urgente pensar o momento presente em termos de globalidade, e de crise de um mundo também decadente. Para tanto, deveria também corresponder ao pensamento uma tomada de posição. Por isso é que a palavra revolução, entendida no sentido duma mudança radical, era a mais justa. $\mathrm{E}$ contra uma civilização burguesa individualista, que impregnava também grandes segmentos da cristandade, e contra as revoluções coletivistas propunha então o retorno a um revigoramento de dois 
conceitos, ou melhor, de duas realidades: a pessoa e a comunidade. Pessoa no seu sentido ontológico mais amplo (corpo e espírito, ser individual e relacional, isto é, interpessoal, movimento de interiorização e de exteriorização), pessoa que não se confunde com indivíduo, consciência, personalidade. Não é possível sintetizar aqui as reflexões e os escritos que Mounier elaborará em torno do binômio pesson é commmidade. Pessoa e comunidade. Pessoa e comunidade exigem uma constante iniciação, porquanto não são realidades estáticas. Por isso, ao

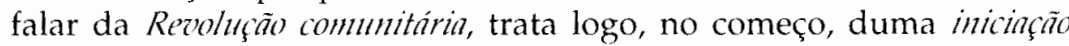
là communidate, duma aprendizagem e dum exercício constante. $\mathrm{O}$ mundo impessoal e anônimo (do oh) formou uma multidão solitária e egoista. Diante desse quadro, o primeiro ato a ser desenvolvido é o duma tomada de consciência de minha vida anônima e o conseqüente despertar para a consciência do eu e do nós, fundantes da comunidade.

"A aprendizagem da comunidade é, portanto, a aprendizagem do próximo como pessoa e na sua relação com minha pessoa, o que foi felizmente chamado de aprendizagem do tu" (p. 100). E será o amor que irá então constituir a unidade da comunidade. Há graus e graus de comunidade, que são as múltiplas maneiras de os homens viverem juntos. No entanto, Mounier reserva o nome de comunidade à única comunidade para ele válida, que é a comnuidnde personalista, que se poderia definir bastante bem como uma pessoa de pessoas (p. 112) comunidade que para os cristãos se realiza na Comunhão dos Santos. E para Mounier a(s) comunidade(s) se estruturam sobretudo por uma adesão a uma escaln de inlor's, "encarnados em pe'ssons destinadas a viver numa total comunidade" (p. 128). E diante da problemática daquele momento histórico (1933-1934), toda uma série de trabalhos abordarão temas que demandavam uma tomada de posição teóricoprática.

Faremos apenas uma referência aos títulos de alguns artigos, a fim de mostrar a atualidade e relevância: Pseudovalores espirituais fascistas, tentação do comunismo, dinheiro e vida privada, prefácio a uma reabilitação da arte e do artista, anticapitalismo, nota sobre o trabalho, nota sobre a propriedade, carta aberta à democracia. E na parte referente às linhas de mítodos $e$ de açöo, serão tratados na perspectiva do personalismo os seguintes assuntos: reformismo e revolução, elogio da força, por uma técnica dos meios espirituais e a revolução contra os mitos. Importante sob todos os aspectos é o tema, longamente estudado, tendo como título Ruptura contre a orde'n cristä e' a désorden estabelecida, tema que serviu de base para aprofundadas e ricas discussões sobretudo nos meios da ação católica.

A questão: Existe llma política cristã? também desencadeou amplos debates sobretudo nos meios político-sociais e religiosos que têm defendido a proposta de partidos e duma democracia cristã. 
II - Da propriedade capitalista à propriedade humana (pp. 361-440). Este livro publicado pela primeira vez em 1934, possui uma atualidade e uma densidade riquíssimas, sobretudo na conjuntura em que vive o Brasil diante duma reforma agrária protelada há séculos. Mounier parte duma posição filosófica, ética e jurídica, poderíamos dizer tradicional, porquanto se fundamenta quase que exclusivamente na doutrina dos Santos Padres, de Santo Tomás de Aquino e nos ensinamentos (encíclicas) dos Papas, em particular Leão XIII e Pio XI. Julga ser a posição mais justa e mais equilibrada, porquanto evita os extremismos da concepção capitalista da propriedade privada, absoluta e intocável, bem como dos coletivismos que negam a dignidade da pessoa enquanto ser livre, responsável e racional. O título da obra é muito significativo: Da propriedade capitalista ì propriedade humann. Uma propriedade capitalista, sobretudo a fundiária (do solo), se caracteriza pelo individualismo possessivo ilimitado, intocável e excludente. O próprio nome "privada" significa exclusão e privação do(s) outro(s). É quase que um direito sagrado e invidável. O próprio código brasileiro chega a ponto de punir mais severamente o roubo e invasão ou o chamado crime contra o patrimônio com penalidades muito mais graves do que os do homicídio ou assassinato. É um absurdo inaceitável sob a óptica da dignidade humana. Por isso, Mounier, baseado na tradição cristã e numa visão de pessoa e de comunidade, propõe uma outra concepção e uma prática da propriedade, principalmente fundiária, que ele denomina humana. A pessoa precisa de um necessirio itital (necessarium ithie) para atender às exigências de sua vida física. Precisa de um necessário pessonl (ncecssarium personuce) para poder levar uma vida humana: educação, cultura, lazer, esporte, vida pública, vida de família, vida interior. Mounier fala também dum necessário largo (n'icessaire large), para que alguém, possuidor de funçōes mais importantes, possa levar uma vida digna. E aqui chama a atenção para o fato de que o cargo ocupado não pode tomar como critérios de ampliação de sua(s) propriedade(s) a vaidade, o orgulho, a cobiça, o desejo insaciável do prazer e do acúmulo de bens e de riquezas. Lembra que a propriedade tem uma dupla função, humana (p'ssonl) e comlinitária, e que ninguém se pode arvorar como senhor absoluto dos bens materiais, e principalmente dos frutos do trabalho. Ninguém é proprietário absoluto da terra, porquanto Deus a criou para o bem de todos.

Realmente o texto condensa toda uma longa tradição cristã com uma concomitante fundamentação na filosofia, na ética e no direito, que em muito poderia ajudar a esclarecer os debates que se travam hoje no Brasil e alhures principalmente com respeito à ocupação e distribuição de terras de maneira mais justa, mais humana e mais solidária. No Brasil, esse texto tem dado um forte embasamento teórico e prático a importantes trabalhos e movimentos sociais referentes a programas de reforma agrária. Citaremos apenas a obra do ex-Ministro da Reforma e Desenvolvimento Agrário (MIRAD), Nelson Figueiredo Ribeiro, obra 
intitulada Caminhada e esperanģa da reforma agrária - A questão da terra ma Constituinte (Paz e Terra, 1987). Ao propor à Assembléia Constituinte um projeto de reforma agrária, Nelson F. Ribeiro fundamenta seus pressupostos filosóficos e sua teoria social da propriedade na obra de Mounier, copiosamente citada (pp. 62-85).

III - Personalismo e cristianismo. Mounier propõe-se mostrar como uma idéia e, no caso, o cristianismo, conservam a atualidade quando permanentemente vividos no seu vigor originários. "Não se pode esquecer que este absoluto é um absoluto vivo, uma prova histórica permanente. Não há momento em que ele (o cristão) possa se desincumbir de inventar sua resposta aos enigmas da história, às iniciativas profanas, às criações e aos erros das civilizações" (p. 442). Do cristianismo, dentre as múltiplas contribuições, trazidas com a "boa nova", pode-se lembrar a riqueza filosófica e teológica transmitida ao pensamento e à vida espiritual do Ocidente com a visão de pessoas, da origem e destinação comuns dos homens. A mensagem cristã começa com um apelo para mudar "o coração de vosso coração". Dei éstis, (vos tornareis um Deus). Diante dessa mensagem, a exigência mais imediata duma vida pessoal reside na resposta: Adum (Presente!) porquanto o cristão é um ser que assume e se compromete. Para tanto, Mounier lembra a necessidade dum exercício constante de depossessão (dípossession), que nos desperta para a disponibilidade. Cita então a frase evangélica: Nihil habentes et omnin possidentes, bem como a de G. Marcel: "a tentação de pensar que nada ter, é não ser mais nada" (p. 465). No entanto, Deus na sua revelação simplesmente respondeu: Sum qui sum. Outro comentário, muito rico, é o referente à parábola de Jesus: o homem que ia de Jerusalém e Jericó. Mostra a grandeza do acolhimento, a "revelação do próximo", enfim uma nova idéia de pessoa.

Pela leitura da temática abordada em Refaire la Renaissancé pode-se constatar sua relevância e atualidade. Um aprofundamento dos conceitos de pessoa e comunidade, enriquecidos pela feliz expressão acrescentada por Paul Ricoeur ("en instituiçốs justas"), poderá ampliar as análises e diagnósticos da nossa civilização, apontando ao mesmo tempo estratégias de ação e de mudanças. 